\title{
A ECONOMIA MERCANTIL E A URBANIZAÇÃO: O GRUPO DO- MICILIAR NA ÁFRICA SUB-SAHARIANA
}

\author{
Alexandre Monteiro Baia*
}

\section{RESUMO:}

O artigo expõe como a penetração da economia mercantil colonial, a cidade e a urbanização desestruturaram as bases de reprodução das sociedades africanas pré-coloniais e a linhagem como sistema familiar na África sub-sahariana. A imposição de princípios sócio-culturais centrados na primazia do indivíduo construiu um grupo domiciliar peculiar constituído por uma família nuclear - como elemento central - e pelo agregado familiar (uma fração composta por parentes consangüíneos ou não). A especificidade da urbanização na África sub-sahariana, a pobreza urbana e as estratégias adotadas pelos atores da produção espacial urbana engendram um mosaico de solidariedades que giram em torno do grupo domiciliar - o que coloca esta categoria no cerne da análise do espaço urbano.

\section{PALAVRAS-CHAVE:}

Economia mercantil; urbanização; África sub-sahariana; espaço urbano; grupo domiciliar.

\section{ABSTRACT:}

The article exposes how the colonial mercantile economy, the city and urbanization have broken the reproduction base of pre-colonial African societies and the lineage as familiar system in subSaharan Africa. The imposition of sociocultural principles centered on the individual primacy has led to the formation of a peculiar household composed by the nuclear family - in the core - and the familiar aggregate (a fraction composed by consanguine relationship or not). The urbanization specificity in sub-Saharan Africa, the urban poverty and the strategies adopted by the actors of urban spatial production generates a mosaic of solidarities which have the household in their core - that poses this category as central in the urban space analysis.

\section{KEY WORDS:}

Mercantile economy; urbanization; sub-Saharan Africa; urban space; household.

\section{I- Os sistemas familiares na África sub- sahariana \\ A análise dos processos decorrentes da formação do Estado-nação, da urbanização e ou da modernidade na África sub-sahariana tem que tomar em consideração as transformações que eles provocam nos sistemas familiares. Pois, os sistemas familiares como quadros de enunciação e de transmissão de valores}

encontram nesses processos novos campos de extensão.

No período anterior à colonização européia os sistemas familiares da África sub-sahariana eram classificados, segundo o modo de afiliação dos indivíduos, em patrilineares - quando a afiliação do indivíduo era feita em relação ao grupo consangüíneo do pai, - matrilineares (pertença ao grupo da mãe) e bilineares. Os 
modos de afiliação engendravam grupos coletivos designados linhagens (matrilineares ou patrilineares) que com a sua dimensão territorial constituíam a tribo igualmente designada clã. Assim, construíase uma trama que incluía cada indivíduo ao mesmo tempo em que o vinculava aos outros indivíduos por conexões genealógicas dentro de determinados espaços e ou territórios.

A reprodução social e econômica da linhagem envolvia manipulações sociais que nem sempre se reduziam às regras de parentesco; como a estratégia de acumular dependentes para garantir mão-de-obra para o trabalho agrícola ou de mineração - que caracteriza as linhagens como unidades econômicas onde se desenvolviam todas as facetas da atividade social num sentido mais amplo. Aí, a divisão etária e sexual do trabalho ocorria em função dos constrangimentos do meio e da situação econômica, constituindo, em última análise, as bases da valorização do trabalho no seio das linhagens.

\section{II- A penetração colonial e a atomização do grupo domiciliar}

Durante o período colonial as práticas sócio-culturais africanas foram freqüentemente reprimidas, pela força ou pela intimidação e depois administradas num quadro de políticas de valorização; pois, eram consideradas como provas de selvajaria ou de primitivismo e que deveriam ser combatidas de forma direta ou indireta (refira-se o uso das missões cristãs como braço de ferro desse combate). O que se designou de administração direta, para o caso de Moçambique, consistiu na criação de uma chefatura indígena como extensão do poder colonial que permitiu contornar o controlo draconiano colonial e graças a sua colaboração viabilizar os projetos de valorização no seio das sociedades linhageiras.
Os resultados da dominação colonial foram tais, que de um lado, provocaram rupturas e crises nas antigas ordens sociais e, por outro lado, suscitaram outras formas de reprodução social. Como relata Dozon (1986), a conquista colonial dispersou as sociedades africanas, e com os dispositivos repressivos da administração, as práticas sociais e econômicas cessaram de ocorrer ou estagnaram-se: as redes de troca e de comércio foram inteiramente paralisadas. Assim, o sistema de linhagem amputado a partir das suas bases de reprodução social e econômica contraiu-se em si mesmo radicalizando as suas lógicas internas.

Com o novo cenário social, a valorização das colônias foi concretizada pela introdução sistemática do cultivo de produtos para exportação. Nesse processo foram utilizadas instituições familiares, comunidades de linhagens e aldeias - quer através do uso da força ou por outros meios de pressão ou sedução dentro de poucos anos populações inteiras passaram a dedicar-se ao cultivo de produtos para exportação. As sociedades africanas apropriaram-se da agricultura comercial mantendo as estruturas da linhagem, mas, criaram novas diferenciações sociais a partir das quais passaram a se reproduzir ajustando as regras e procedimentos aos novos dados econômicos: a introdução da economia das plantações - cultivo de oleaginosas, de algodão, sisal e cana sacarina para exportação.

"Com a [eliminação] das atividades sócio-econômicas segundo moldes précoloniais e com a expansão das culturas arbustivas, as matrilinhagens e patrilinhagens deixam de ser grupos em corpo; as formas de cooperação que outrora animavam os grupos de filiação dão lugar a um processo de individualização. Cada membro duma linhagem torna-se plantador separado e cultiva, com a sua esposa, (...) seus filhos e eventualmente um colateral próximo, suas próprias parcelas; por esse 
processo, a terra torna-se propriedade [individual], ao contrário do sistema fundiário antigo onde [a terra] era apropriada coletivamente e era objeto de um direito de uso individual." (Dozon, 1986, p. 323)

Nesse processo a linhagem tornou-se o teatro de numerosos conflitos, de estratégias e contra-estratégias. A sua força passou a residir no fato de tolerar a emancipação progressiva de uns e as prerrogativas de outros dentro de um quadro simbolicamente coerente - aí onde as sociedades linhageiras transformaram-se num cenário criado por relações mercantis, de apropriação privada e em torno de famílias restritas - gerindo o antigo e o novo sem uma ruptura radical.

O estabelecimento da economia das plantações marca, por um lado, a transformação do cultivador tradicional em camponês integrado na economia mercantil e sujeito às imposições do Estado colonial e, por outro, a passagem de um sistema familiar, cuja estrutura formava grupos coletivos - as linhagens como a essência das comunidades produtivas baseadas no direito costumeiro da terra e cujos membros se encontravam vinculados socialmente através de laços de parentesco - para um sistema familiar mais restrito onde os antigos laços sociais são transformados ou reinventados em torno de uma nova categoria social atomizada: o grupo domiciliar.

\section{Os grupos domiciliares e a urbanização}

Os processos de transformação social na África sub-sahariana, através dos quais as tradições são comprometidas e/ou reinventadas, foram (e são), também, engendrados pela criação de cidades e pela urbanização. A urbanização tornou-se um fenômeno de massa somente após a independência (descolonização) dos paises africanos.

"Ela [a urbanização] está ligada a instauração dos Estados, a criação de serviços públicos, a implementação de políticas de desenvolvimento que ao serem direcionadas principalmente aos meios rurais, provocam paralelamente as migrações para as cidades. Múltiplas razões para isso: a escolarização, as contradições próprias às sociedades locais, (...) as possibilidades de um emprego assalariado e, sobretudo, a atração própria do meio urbano que representa uma alternativa ao modo de vida aldeã [portanto, rural]. (...) Sob diferentes aspetos, o fenômeno urbano apresentou-se como pólo antitético ao mundo rural e tradicional. Ele organiza novas relações sociais dispersando e distribuindo os indivíduos e os grupos em espaços diferenciados (lugar de trabalho, lugar de habitat, etc.) segundo critérios de ordem sócio-econômica ou sócio-profissional. Ele ordena novos modos de distinção social $(\ldots)^{\prime \prime}$. (Dozon, 1986, p. 328)

Os processos engendrados pelo fenômeno urbano tendem para uma ruptura efetiva com o mundo tradicional (e/ou rural), assim espera-se, por hipótese, que os sistemas de parentesco, já transformados pela economia das plantações, se rompam definitivamente e que deixem um campo vasto e livre para o estabelecimento de famílias nucleares - universos estritamente privados modelados sobre maneiras ditas ocidentais ou modernas. No entanto, a complexidade do processo mostra que se por um lado se produz um meio urbano de transformações reais, elas não conduzem necessariamente a esse modelo familiar.

Como foi mencionado, o meio rural e as estruturas da linhagem, em particular, foram já modificadas durante a época colonial - sendo votadas às práticas e às estratégias de famílias restritas, - nesta perspectiva o mundo urbano e salarial tende 
a agravar essas transformações, entre elas a tendência para a atomização do grupo domiciliar num processo que apesar das mudanças, continua marcado pelo sistema linhageiro.

Por exemplo, em Moçambique, e para a África sub-sahariana em geral, apesar da migração campo-cidade, vulgarmente considerada excessiva, e do suposto gigantismo das cidades-capitais nacionais, o meio rural ou o campo ainda é preponderante. Perante uma fraca ou ausente industrialização, a migração campocidade é limitada e a agricultura permanece sendo uma atividade econômica principal da população - contudo, torna-se necessário analisar o meio urbano tendo em consideração as suas relações com o meio rural; pois, não se pode falar duma oposição radical entre as duas realidades ou mesmo entre práticas vinculadas a uma realidade dita moderna e um universo supostamente tradicional, senão de um tecido de laços orgânicos entre os dois pólos.

"(...) os citadinos, por mais distantes que se encontrem do lugar de origem, não escapam ou pouco se desfazem das suas obrigações linhageiras. Eles participam notadamente nos funerais, dão um subsídio suplementar àqueles eventos privilegiados onde se atualizam ainda os sistemas linhageiros, (...) [assim] as relações entre citadinos e os meios linhageiros são antes de respeito do que de desprezo" (Dozon, 1986, p. 330)

Apesar das relações fluidas que ocorrem entre o meio urbano e o meio rural, é necessário notar que o meio urbano secreta práticas sociais que rompem efetivamente com o sistema linhageiro - isso ocorre como conseqüência da separação espacial de famílias parentas que se desenvolvem diferencialmente em função do seu nível econômico e da sua pertença a outro grupo social. Contudo, essas famílias, na sua maioria, não correspondem à família nuclear: elas tendem a restringir o número dos seus membros, mas não atingem o nível elementar de um casal e seus filhos; daí a relevância do conceito de grupo domiciliar. Pois, trata-se de uma morfologia familiar composta e alargada que qualifica as ditas famílias urbanas africanas - verdadeiras unidades domiciliares por vezes constituídas por duas ou mais famílias nucleares vivendo sob o mesmo teto ou uma família nuclear rodeada por várias pessoas tendo um laço de parentesco com um dos membros da família nuclear; mas, também, grupos em que nem todos os membros estão ligados por laços de parentesco consangüíneos ou tradicionais. Pois, a morfologia dos grupos domiciliares urbanos varia em função de obrigações particulares, escolhas, afinidades e interesses diversos. Por isso, na África sub-sahariana:

"O meio urbano gera assim [grupos domiciliares] originais, inéditos, que, todavia, pousam sobre as redes de parentesco e as gere segundo formas de uma geometria variável não reproduzindo a ordem estrita da linhagem. Elas resultam do compromisso entre a tendência para a restrição e a exigência de solidariedades efetivas". (Dozon, 1986, p. 331)

Segundo as normas e práticas costumeiras da linhagem, a sociabilidade e/ ou a hospitalidade de uma família é medida através da sua atitude em relação à oferta e recepção de bens e serviços domiciliares, tais como alimentos, acolhimento de parentes, entre outros. Desse modo, tornase prática corrente e comum que uma família nuclear permita a convivência com outros indivíduos parentes ou não, mas com base em princípios de mútua confiança. De acordo com De Schlippe (1956, p. 135), a oferta e recepção de alimentos têm uma importância social e simbólica na distribuição da riqueza entre membros de uma linhagem. As normas que regem a sociabilidade, e a hospitalidade, sustentam que a distribuição ou partilha de alimentos, principalmente confeccionados, é 
um atributo de autoridade e prestígio e que a sua recepção coloca o receptor numa posição que o obriga a retribuir com respeito, serviço ou uma hospitalidade recíproca.

A urbanização na África sub-sahariana prossegue, constrangida pelas atividades agrícolas, com a ampliação da migração campo-cidade que esgota as possibilidades de emprego oferecidas pelo Estado e pelas empresas. Nessas condições, os grupos domiciliares na cidade preenchem as funções das instituições de acolhimento e de segurança social; pois, constituem, por vezes, uma força real: seja porque presidem o exercício de uma profissão artesanal, o funcionamento de um pequeno comércio ou de uma pequena empresa, seja porque ele corresponde a exploração agrícola nas áreas peri-urbanas ou às estratégias imediatas de ocupação do solo.

A incorporação das sociedades africanas na economia monetarizada e na cidade não destruiu a produção agrícola de subsistência. Os grupos domiciliares, na sua maioria, não possuem meios financeiros nem técnicas que permitam mudar os métodos tradicionais de cultivo. No entanto, a produção agrícola e seus métodos asseguram, em muitos casos, que cada grupo domiciliar possa sustentar a si próprio através de uma produção voltada não apenas para o consumo doméstico, mas também, para a venda nos mercados locais legalizados ou não legalizados. A prática da agricultura - que também constitui o suporte para o trabalho assalariado - leva a que os grupos domiciliares permaneçam nas cidades não apenas como cultivadores, mas e até, como grupos semi-proletarizados. Pois, geralmente, é um membro, homem adulto, que consegue obter um emprego nos setores modernos de atividade e que, portanto, contribui com uma renda em dinheiro proveniente do trabalho fora da esfera familiar ou domiciliar, ou seja, do trabalho assalariado - e isso apesar dos baixos salários para uma mão-de-obra geralmente não qualificada.

Certas características dos grupos domiciliares na cidade são reforçadas ou minimizadas por relações mais globais e pelas tramas de estratificação social em que se inserem. A solidariedade familiar, nesse quadro, tende a se difundir no conjunto do corpo social atravessando os diferentes estratos da sociedade: ela obriga a distribuição e cria situações em que, não apenas em áreas contíguas, mas, sob o mesmo teto coabitem pessoas de estatutos sócio-econômicos muito diferentes - o que apenas é limitado pelas classes mais privilegiadas pela economia que se esforçam em manter o seu universo familiar restrito. Mas, em geral, ocorre como se a solidariedade familiar se concentrasse no laço nodal da estratificação social urbana atravessando-a até o limite onde atuam outras práticas e estratégias familiares. Deste modo, pode-se afirmar que, como refere Dozon (1986, p. 332), em alguns casos, os determinantes dos grupos domiciliares na cidade, da sua morfologia, estão menos em função de obrigações ligadas a tradição que em função das condições sócio-econômicas: um citadino pobre e visivelmente sem futuro não é nunca solicitado pela sua rede de parentesco.

Os centros urbanos na África subsahariana resultaram fundamentalmente do crescimento de antigos centros de trocas comerciais situados ao longo de rotas comerciais ou nos portos para exportação de matérias primas para as metrópoles coloniais. Pela sua arquitetura as cidades coloniais foram concebidas a imagem e semelhança da cidade européia e com normas restritivas que pressupunham ser habitadas pela população colonizadora de origem européia ou caucasiana. A presença da população negra nessas cidades estava regulada por estatutos classificatórios que distinguiam duas categorias de cidadãos: cidadão de primeira - designação da 
população de raça branca (européia) localizada no centro da cidade ou no espaço urbano vulgarmente chamado de cidade de cimento (com arquitetura européia) - e cidadão de segunda (população negra) residente nos subúrbios ou na periferia. A ordem social estabelecida configurava desde então um espaço dividido ou segregacionista.

Para legitimar o suposto caráter civilizatório da raça caucasiana (ou branca) e como resultado do encontro entre dois modos de vida diferentes, o das sociedades européias com o das sociedades africanas, construiu-se um termo transitório: o de uma população assimilada constituída por negros que demonstravam ter incorporado valores europeus, considerada destribalizada e por isso permitida a viver nas cidades.

Wilson (1941, 1942), citado em Watson (1958), e Hannez (1980) sustentam que no conceito de destribalização está implícito um processo caracterizado pela escolha pelos africanos do sistema de valores e relações sociais baseado na produção industrial que a ocidentalização impunha - o que ocorria em detrimento do sistema baseado na produção de subsistência tradicional - significando que a absorção dos africanos na cidade e no emprego industrial ou em setores de atividade, ditos modernos, dissolvia as relações sociais tribais e os valores morais nelas implícitos (Watson, 1958:5). Na realidade, a destribalização foi um processo exageradamente e ideologicamente concebido. Pois, o impacto da ocidentalização na população negra africana exprimiu-se fundamentalmente na adoção da vestimenta européia, da cultura material e de formas exteriores de comportamento; portanto, a assimilação não implica necessariamente destribalização. Porque, concordando com Watson (1958), a população africana nas cidades mantém as solidariedades e hostilidades tribais, forma grupos de ajuda mútua ou associação preferencialmente com membros da mesma tribo. Portanto, os grupos domiciliares africanos mantêm as sociabilidades construídas a partir de princípios inerentes à linhagem.

\section{IV-Por fim}

\section{a) O enfoque no grupo domiciliar na análise do espaço urbano}

As exposições anteriores revelam como cada membro do grupo domiciliar sujeito às especificidades da vida urbana derivadas principalmente pelas relações no lugar de trabalho assalariado - volta ao seu sistema de relações e de valores sociais, ditos tradicionais, na esfera doméstica. De tal modo, que apesar dos indivíduos levarem idéias de uma esfera para outra nenhum membro procura introduzir um novo sistema de relações e de valores sociais na unidade domiciliar. Por isso, a hipótese aponta para a permanência do grupo domiciliar como uma unidade social e econômica dentro da cidade com um modo de vida marcadamente influenciado pelos sistemas de linhagem, tanto transformados como reinventados. As influências mútuas das duas esferas, moderna e tradicional, estão condicionadas pelo grau de inserção na economia urbana. É assim que os grupos domiciliares estabelecem um compromisso entre a opção de respeitar a tradição e a submissão às novas realidades. Nota-se, assim, que os sistemas de linhagem, conjugando transformações e persistências, tomaram conta da produção e dos produtores e asseguram, no sentido mais amplo, a reprodução social.

O grupo domiciliar na África subsahariana encontra-se num cruzamento de três vertentes: (i)aquela que procura conservar os sistemas linhageiros, apesar das transformações impostas pela cotidianidade moderna, nos moldes do mundo rural ou das sociedades pré- 
coloniais; (ii) a concernente às cidades, que ainda em conexão com a primeira, revela conjuntos de grupos domiciliares inéditos, menos estruturados desenvolvendo-se numa espécie de compromisso entre o respeito às tradições e as necessidades sócio-econômicas do tempo e espaço presentes e (iii) a que tende a estabelecer um modelo de práticas familiares mais ou menos similares às maneiras ditas ocidentais ou modernas, promovida por frações de população privilegiada economicamente e pelo Estado.

O meio urbano alberga, portanto, as três vertentes propiciando um contexto em que os grupos domiciliares, envoltos em contradições, dão respostas mais ou menos eficazes às dificuldades mais diversas. Essas dinâmicas indicam que o desenvolvimento dos grupos domiciliares africanos na cidade está intrinsecamente ligado ao da sociedade no seu conjunto. Pois, que a pobreza crescente e o subdesenvolvimento ou reforçam as solidariedades que caracterizavam as linhagens ou, inversamente, acentuam rupturas entre camadas sociais, assim, cristalizando as desigualdades.

O grupo domiciliar tornou-se a arena social básica para a tomada de decisões sobre o status, o poder, a propriedade e o trabalho entre homens e mulheres, gerações e parentes. Para além de o conceito estar ligado à estrutura física da habitação e da cozinha ou às relações de parentesco, o grupo domiciliar deve ser visto como um ponto de cruzamento de redes de relações sociais sem nenhuma subordinação clara nem entrelaçamentos perfeitos com outras redes. Em comunidades - freqüentes nas cidades africanas - os grupos domiciliares continuam a ser estruturas fundamentais que asseguram os rendimentos e a sobrevivência, isso, num contexto em que o acesso aos meios de reprodução, espaço urbano e habitação constitui um aspecto crítico da economia urbana. Por isso, o grupo domiciliar não é apenas uma unidade de consumo, mais do que isso, ele é uma unidade econômica ou de produção voltada, fundamentalmente, para a subsistência e reprodução da força de trabalho assalariada.

\section{b) As variações espaciais decorrentes das desigualdades dos grupos domiciliares}

O enfoque no grupo domiciliar na análise do espaço urbano e da cidade na África sub-sahariana torna-se crucial, uma vez que a paisagem urbana produzida é explicada, também, pelas dinâmicas engendradas por esse ator no seu cotidiano.

A paisagem das cidades na África sub-sahariana revela como as três vertentes que caracterizam os grupos domiciliares se manifestam no espaço urbano. A diferenciação residencial, as desigualdades no acesso ao solo urbano e a distribuição desigual das infra-estruturas urbanas no espaço urbano culminam com o surgimento de três áreas diferenciadas. Derivando de exemplos das cidades de Moçambique, as variações espaciais no meio urbano produzem uma paisagem com três áreas distintas:

\section{i) Primeira área}

A primeira área, onde as habitações de caniço estão a ser gradualmente substituídas por cimento e zinco, abriga grande parte da população que migrou do campo para a cidade. Nesta área os grupos domiciliares mantêm uma vida social mais próxima dos sistemas familiares anteriores à colonização portuguesa. A ocupação do solo é considerada ilegal e espontânea e por isso é desencorajada a construção definitiva. Os residentes recorrem aos serviços de educação e de saúde localizados nos bairros suburbanos vizinhos.

O fornecimento de água canalizada, energia elétrica e telefonia fixa é ausente ou deficiente à semelhança da maior parte dos bairros suburbanos: (i) têm abrangência muito restrita; (ii) estão sujeitos a 
constantes avarias/cortes; (iii) e os que não conseguem cumprir com os requisitos para um acesso oficial operam com ligações clandestinas. Nem sempre as vias de acesso estão asfaltadas e carecem de iluminação pública. As vias não pavimentadas são de difícil transitabilidade e estão sujeitas a erosão na época chuvosa, dada a falta de sistema de drenagem de águas pluviais.

A coleta e o tratamento de resíduos sólidos estão a cargo de iniciativas dos residentes locais: enterro do lixo nos quintais ou o seu carregamento em carrinhos artesanais movidos pela força humana ou então, o lixo é amontoado em algumas esquinas de ruas, em crateras abertas pela erosão ou em valas de drenagem.

O sistema de drenagem das águas pluviais é constituído por valas a céu aberto em forma de " $v$ " e restringe-se às bermas das ruas pavimentadas. Este sistema, já de si deficiente, enfrenta problemas resultantes da falta de manutenção, sendo comum encontrar valas degradadas e cobertas de lixo, o que dificulta o escoamento da água.

Esta área não dispõe de sistema de esgotos e, por isso, as águas residuais são despejadas nos quintais ou mesmo nas ruas. O uso de latrinas melhoradas é predominante, embora alguns grupos domiciliares usem latrinas ditas tradicionais (sujeitas ao desabamento durante a época chuvosa) ou simplesmente não possuem qualquer tipo de latrina.

\section{ii) Segunda área}

A segunda área é caracterizada pela predominância de habitações ditas melhoradas (construídas de cimento e zinco). A ocupação das parcelas de terra ocorre com assessoria das autoridades municipais responsáveis pela delimitação das parcelas, dos arruamentos e pela aplicação de requisitos mínimos urbanísticos. Os residentes desta área - tendo adotado alguns aspectos da vida urbana do tipo ocidental - consideram-se com uma cultura urbana superior a dos residentes da primeira área e por isso procuram manter vínculos com o núcleo central da cidade, ainda que tenham que percorrer grandes distâncias.

O fornecimento de energia elétrica, água canalizada, telefonia fixa e televisão à cabo têm maior abrangência e é de melhor qualidade que na área anterior, havendo casos em que, por exemplo, há cortes de energia que abrangem a primeira área mas não afetam a segunda. Nem todas as vias de acesso são pavimentadas e, em alguns casos, carecem de iluminação pública.

Esta área não possui sistema de drenagem de águas pluviais. Os resíduos sólidos são depositados em contendores geridos pelos serviços municipais, mas o seu tratamento enfrenta problemas comuns à cidade inteira; é assim, que não raras vezes, o lixo acumulado excede a capacidade dos contendores e pode levar vários dias sem que seja removido.

As casas estão providas de um sistema de latrinas melhoradas e há uma tendência para sua substituição por sanitários modernos. Algumas residências possuem um sistema de fossas cépticas que garante o escoamento dos esgotos e das latrinas melhoradas para um coletor onde os resíduos ou são absorvidos pelo solo ou são drenados por camionetes de sucção.

\section{iii) Terceira área}

A terceira área é caracterizada por construções arquitetônicas, semelhantes às dos bairros mais prestigiados da antiga cidade colonial, que revelam, à partida, elevados investimentos de capital financeiro na construção da habitação. Nesta área são comuns moradias unifamiliares com dois ou mais pisos ou condomínios luxuosos fechados. Trata-se de uma área onde residem famílias que tendem a romper os seus vínculos com os hábitos e costumes inerentes aos sistemas de linhagem. Pois, 
o alto poder aquisitivo e a experiência relativamente longa de vida na cidade culminam com o aumento da distância social tanto com os grupos domiciliares das áreas anteriores e como com as práticas relativas às linhagens que caracterizam o meio rural.

Os residentes desta área recorrem frequentemente ao uso de serviços privados (ex: de educação, saúde) prestados na sua maioria no centro da cidade ou dos que atraídos pelos novos consumidores começam a se fixar dentro ou na proximidade dos "novos enclaves" residenciais.

Os serviços de abastecimento de energia elétrica e água canalizada, de telefonia fixa e televisão à cabo são de melhor qualidade que nas áreas anteriores. As vias de acesso são pavimentadas e beneficiam de iluminação pública.

A área possui um sistema de recolha e tratamento de resíduos sólidos gerido por empresas privadas, redes subterrâneas de drenagem de água pluvial e sistemas de esgotos, munidos de componentes para o tratamento e reciclagem da água.

As dinâmicas descritas nas secções anteriores produziram um espaço qualitativamente novo que contém em si oposições, contradições e conflitos transpostos da sociedade para o espaço. Pois, as variações espaciais no meio urbano tendem a refletir as desigualdades e hierarquias derivadas da estratificação social resultante da distribuição desigual da renda e da habitação - fatores que induzem a diferenciação residencial e explicam a paisagem urbana diferenciada. Visto que a distribuição dos lugares residenciais opera agrupamentos em função da capacidade financeira dos sujeitos - estratificação social - e onde a distância social tende a ganhar uma forte expressão espacial, coloca-se em foco a segregação urbana.

\section{Bibliografia}

AMIN, S. O Capitalismo e a renda fundiária; a dominação do capitalismo sobre a agricultura. In: AMIN, S. E VERGOUPOLOS, K. A Questão camponesa e o Capitalismo. Utopia Camponesa. Portugal: a Regra do Jogo Edições, 1978.

ARAÚJO, M. G. M. O sistema das aldeias comunais em Moçambique; transformações na organização do espaço residencial e produtivo. Ph.D. diss. Universidade de Lisboa, 1988.

BAIA, A. H. M. Ruralidades na cidade de Nampula; exercício teórico para uma crítica a Cidade. Msc. diss. Universidade de São Paulo, 2004.

BEAUJEU-GARNIER, J. Geografia Urbana. 2a ed. Lisboa, 1995.

BECKER, C. M. et al. Beyond urban bias in Africa: urbanization in an era of structural adjustment. London: 1994.
CARLOS, A. F. A. Uma Leitura sobre a cidade. In: Cidades, Vol.1, No 1. Presidente Prudente: 2004.

CASTELLS, M. City, class and power. Macmillan, 1978.

CASTELLS, M. La Cuestión Urbana. México. Siglo: veintuno (quarta edição), 1977

COUSSY, J. et VALLIN, J (dir.). Crises et Population en Afrique: crises économiques, politiques d'ajustement et dynamiques démografiques. Les études du Ceped, n० 3, 2a. ed. CEPED. Paris: 1996

DOZON, J-P. En afrique, la famille à la roisée des chemins. In: BURGUIÉRE, A. et al. Histoire de la famille; le choc des modernités. Tome 2. Paris: Armand Colin, 1986. pp. 301-338.

DUBRESSON, A. Prodution et produteur dans les espaces urbains. In: Afrique Contemporaine: 
Villes d'Afrique, nº168, Octubre-Décembre. 1993. pp 171-186.

FANON, F. Os Condenados da Terra. Rio de Janeiro: Civilização Brasileira, 1968.

FERNANDO, M. E. Gestão Urbana: recolha e tratamento de lixo sólido doméstico nas cidades moçambicanas. MICOA. Maputo: 1996. (mimeo)

FERREIRA, J. S. W. Globalização e Urbanização subdesenvolvida; São Paulo em perspectiva, (14)4. 2000. In: www.scielo.br/pdf/spp/V14n4/ 9748.pdf - 29/08/05.

GONÇALVES, A. C. Os bairros urbanos como lugares de práticas sociais. Revista da Faculdade de Letras - Geografia. Porto. 1988. Série I, Vol. IV, pp. 15-31.

HARVEY, D. Los Límites del Capitalismo y la Teoria Marxista. México: Fundo de Cultura Econômica. 1990.

HANNEZ, U. Exploring the city: inquiries toward na urban anthropology. New York: Columbia University, 1980.

IBRAIMO, M. A. Crescimento da população urbana e problema da urbanização da cidade de Maputo. UPP/CNP. Série População e Desenvolvimento. Doc. 11. Maputo: 1994.

LEFEBVRE, H., La Vie Quotidienne dans le Monde Moderne. Paris: Gallimardi, 1968.

A Re-Produção das Relações Sociais de Produção. Porto: Escorpião, 1973.

De lo Rural a lo Urbano. Barcelona: Edicions 62, 1973b. 1995.

The production of space. Oxford: Blackwell.

MALAUENE, D. Alterações na Paisagem do bairro da Polana Caniço na cidade de Maputo. Trabalho de Lic. em Geografia. FLCS/UEM. Maputo: 2006 (mimeo).

MATOS, E. A. C. Serviços urbanos básicos nos bairros da Maxaquene "A" e da Urbanização. Trabalho de Lic. em Geografia, FLCS/UEM. Maputo: 2005 (mimeo).
MUANAMOHA, R. C. Dinâmica do crescimento populacional no período pós-Independência em Maputo. In: Urbanização acelerada em Luanda e Maputo - Impacto da guerra e das transformações sócio-económicas (década de '80 e '90). CesA. Estudos de Desenvolvimento no 7. 2002. pp. 1119.

OBUDHO, R. Population distribution in Africa: Urbanization under weak economic conditions. In: Population, Distribution and Migration. New York: 1994

OPPENHEIMER, J. \& RAPOSO, I. A pobreza em Maputo. Departamento de Cooperação/MTS. Lisboa: Colecção Cooperação, 2002.

POURTIER, R. L'explosion urbaine. In: Afrique Contemporaine: Villes d'Afrique, n0164, OctubreDécembre. 1994. pp 153-167.

TSANDZANA, A. F. Estudo da expansão horizontal da cidade de Maputo; o caso do Bairro de Laulane. Trabalho de Lic. em Geografia FLCS/ UEM. Maputo: 1999. (mimeo)

UNDP/UNCHS, Housing and Living Conditions in peri-urban areas of Maputo city. MC\&WA. Republic of Mozambique.

WALLESTEIN, I. Capitalismo histórico e Civilização capitalista. Rio de Janeiro: Contraponto, 2001.

WATSON, W. Tribal Cohesion in a money economy; a study of Mambwe people of northern Rhodesia. Manchester: Manchester University, 1958.

WOLF, E. G. Sociedades camponesas. Curso de Antropologia urbana. Rio de Janeiro: Zahar Editores, 1970.

Trabalho enviado em março de 2007

Trabalho aceito em julho de 2007 